\title{
Comparative study on microbial enhanced oil recovery using mannosylerithritol lipids and surfactin
}

\author{
Cristiano José de Andrade 1,2 *, Gláucia Maria Pastore 2 \\ ${ }^{1}$ Department of Food Science, Faculty of Food Engineering, University of Campinas - Av. Monteiro Lobatto, \\ Campinas-SP, Brazil, Postcode 13083-862 \\ ${ }^{2}$ Polytechnic School of the University of São Paulo - Av. Prof. Luciano Gualberto, São Paulo-SP, Brazil, Postcode 05508-010 \\ *Corresponding author E-mail: eng.crisja@gmail.com
}

\begin{abstract}
Worldwide oil production has been declining. Microbial enhanced oil recovery is one of the most important tertiary recovery processes. The aim of this work was to evaluate the surface activity properties of surfactin and mannosylerithritol lipids-B. In our previous studies, surfactin and mannosylerithritol lipids were produced using cassava wastewater as substrate and then purified by ultrafiltration. Thus, this work extends our previous studies. Experiments of surface activity under extreme conditions (temperature, ionic strength and $\mathrm{pH}$ ), oil displacement, removal of oil from sand and emulsification index were carried out. Central composite rotational design was performed under extreme conditions of temperature, $\mathrm{pH}$ and ionic strength. The results indicated that ionic strength significantly affected the surface activity of surfactin. On the other hand, ionic strength, but also temperature and $\mathrm{pH}$ significantly affected the tenso activity of mannosylerithritol lipids-B. Regarding oil displacement test, mannosylerithritol lipids-B showed higher clear zone than surfactin. Contrary, in the experiments of removal of crude oil from sand, minimal differences were observed between surfactin and mannosylerithritol lipids-B. Therefore, both surfactin and mannosylerithritol lipids-B showed good surface activity under extreme conditions. In addition, it seems that mannosylerithritol lipids-B is subtly better than surfactin for microbial enhanced oil recovery.
\end{abstract}

\begin{tabular}{ll}
\hline Nomenclature & \\
\hline American Petroleum Institute (API) & Central composite rotational design (CCRD) \\
Microbial enhanced oil recovery (MEOR) & Critical micelle dilution (CMD) \\
Mannosylerithritol lipids-B (MEL-B) & \\
\hline
\end{tabular}

Surface tension (ST)

Keywords: Cassava Wastewater; Central Composite Rotational Design; Mannosylerithritol Lipids; Microbial Oil Enhanced Recovery; Surfactin.

\section{Introduction}

Currently and in the years to come, petroleum has been playing the most important role in energy sectors and also supplies many basic industries (rubber, chemicals, etc). More than $90 \%$ of petroleum production is related to conventional oil, that is, light and medium oils. However, the exploration of heavy and extra heavy oils is increasing rapidly over time [1].

Worldwide, the oil production has been declining due to the increasing demand for energy by the population, physical limit of oil wells, difficulty in finding and exploring new oil fields, in particular conventional oils [1-2]. In this sense, among the different forms of energy generation, fossil fuels represent from $80-90 \%$ [12].

Petroleum, known as crude oil, is a mixture of organic compounds and trace amounts of inorganic compounds including saturated hydrocarbons, aromatic hydrocarbons, nitrogenous and sulfur compounds, asphaltenes, etc. Thus, the different chemical composition of crude oils associated to physical features of oil well (temperature, depth, $\mathrm{pH}$, etc) makes each oil well a unique system [3]. According to American Petroleum Institute (API), crude oils are classified by relative density classified in 4 groups light (API >
31.1), medium (API from 22.3 to 31.1), heavy (API < 22.3) and extra heavy (API < 10.0).

Regarding crude oil production, the underground pressure in well is used as drive force for oil recovery - primary technique - that recoveries $\approx 5-10 \%$ of original oil in well [4]. The secondary technique of oil recovery is very often accomplish by water-flooding (injection of water at top of well), that recoveries $\approx 10-40 \%[1-2$, 4]. Therefore, every stripper well has about $50-85 \%$ of original oil in well $[1-2,4]$. Thus, the aim of enhanced oil recovery technologies is mainly the residual oil in the stripper wells - after the primary and secondary techniques of oil recovery - which is estimated at $\approx 2-4$ trillion barrels [2].

Microbial enhanced oil recovery (MEOR) is one of the most important tertiary recovery processes. Preliminary studies were carried out in the 1950s (US, Eastern Europe, USSR and Netherlands), since then researches in oil production and exploration has indicated that MEOR should be apply in stripper wells (less than $10 \mathrm{oil} \mathrm{barrel/day),} \mathrm{in} \mathrm{which} \mathrm{some} \mathrm{parameters} \mathrm{must} \mathrm{be} \mathrm{taken} \mathrm{into}$ account such as type of formation (sandstone), depth, temperature, pressure, reservoir rock permeability, gravity of oil, viscosity of oil, water cut, $\mathrm{pH}$, residual oil saturation and ionic strength [4]. MEOR technique lies on the application of microorganisms (in situ) or their metabolic (ex situ) into the oil wells. Both, in situ and ex situ MEOR act on the reduction of surface and interfacial ten- 
sion, gas production (increasing the differential pressure driving), selective plugging, biodegradation, and wettability alteration, etc., in which biosurfactants (interfacial tension, emulsification and higher bacterial mobility), polymers (viscosity of flood water and selective plugging), solvents (carbonate rock) and biomass (selective plugging) are used to enhance the oil recovery [4].

The state of art on MEOR indicates the in situ strategy instead of ex situ due to the its lower operating costs, in particular applying indigenous biosurfactant-producing bacteria [4]. In situ MEOR is very often operates in a cyclic manner and experiments at field trial scales were already described, for instance, Le et al. [5] detailed that $6.3 \times 10^{4}$ tons of oil were recovered (in situ strategy) from 518 wells. In this sense, the in situ strategy must be carried out with genetically-engineered microbial consortium (preferably indigenous bacteria that are non-sulfate-reducing) that synthesize large amounts of biocompounds such as biosurfactants, biopolymers, acids, etc. It should be noted that MEOR has advantages over enhanced oil recovery (that applies chemicals for oil recovery), since bioproducts are not derived from petrochemicals, nontoxic, biodegradable, and can be produced using low-cost substrates [4]. However, the in situ strategy produces many compounds such as acids organic, enzymes, biosurfactants etc., in which when associated to different chemical composition of wells, temperature, $\mathrm{pH}$, etc., leads to very low repeatability of experiments [5].

Very likely, MEOR will be become fundamental for the petrochemical industry. Due to the unique features of each well such as temperature, ionic strength, $\mathrm{pH}$, crude oil gravity, lithology, etc., different approaches may be used (microbial consortiums and biocompound mixes) in order to reach yields that are applicable at industrial scale. Therefore, any new approach of MEOR has to be considered valuable.

As mentioned earlier, biosurfactants are one of the most important biocompounds in MEOR. Our previous studies described a low production and purification cost of two biosurfactants, surfactin and mannosylerithritol lipids-B (MEL-B) [6-7]. Therefore, this study describes for the first time, the surface activity of two biosurfactants, MEL-B and surfactin under extreme conditions of temperature, ionic strength and $\mathrm{pH}$ and their interactions (similar conditions to the wells). Then, experiments related to MEOR (removal of crude oil from sand, oil displacement and emulsification index) were carried out using 3 different oils (crude oil gravity) light, medium and heavy.

\section{Materials and methods}

\subsection{Measurement of surface activity}

The surface tension (ST) measurements were carried out by using the plate method at room temperature in a Krüss $\mathrm{GmbH}$ K-12 tensiometer.

The surface activity of produced MEL-B and produced surfactin was measured by central composite rotational design (CCRD) experiments. The critical micelle dilution (CMD) corresponds the ST value of a sample diluted 10 times (CMD-1) and 100 times (CMD-2) [7].

\subsection{Surface activity of mannosylerithritol lipids and surfactin under extreme conditions: $\mathrm{pH}$, temperature and ionic strength}

Surfactin (Lipofabrik) and MEL-B (Toyobo) standard solutions were prepared separately at $100 \mathrm{mg} . \mathrm{L}^{-1}$; whereas MEL-B and surfactin produced solutions were at 869.52 and $75.74 \mathrm{mg} . \mathrm{L}^{-1}$, respectively [6-7]. Our previous studies identified the chemical structures of surfactin and MEL-B, Figs. 1 and 2, respectively [67]. It is worth noting that surfactin was composed by two different sequences of amino acids (Fig. 1).

The surface activity of biosurfactants under extreme conditions of $\mathrm{pH}$, temperature and ionic strength were first investigated individually (each experiment was run in triplicate). The effect of ionic strength on the surface activities of biosurfactants was tested with synthesized brine - g.L $\mathrm{L}^{-1}: \mathrm{Na}_{2} \mathrm{SO}_{4}: 1.26, \mathrm{NaHCO}_{3}: 0.051, \mathrm{NaCl}$ : 0.75, $\mathrm{CaCl}_{2}$ : 9.2, $\mathrm{MgCl}_{2}$ : 7.6, $\mathrm{KCl}: 0.61$ [8]. The synthesized brine concentrations used were $2.5,5,10$ and 20 g.L ${ }^{-1}$, whereas the effect of $\mathrm{pH}$ on surface activity was evaluated at 2 unit basis, from 2 to 12 . The effect of temperature on surface activity was investigated by using 3 different temperatures $\left(79,100\right.$ and $\left.121{ }^{\circ} \mathrm{C}\right)$ for 60 min. After those treatments, the STs and their CMDs were measured.

Thereafter, as shows the Table 1, the CCRD evaluated, for the first time, the interactions effect of temperature, $\mathrm{pH}$ and ionic strength in surface tension activity.

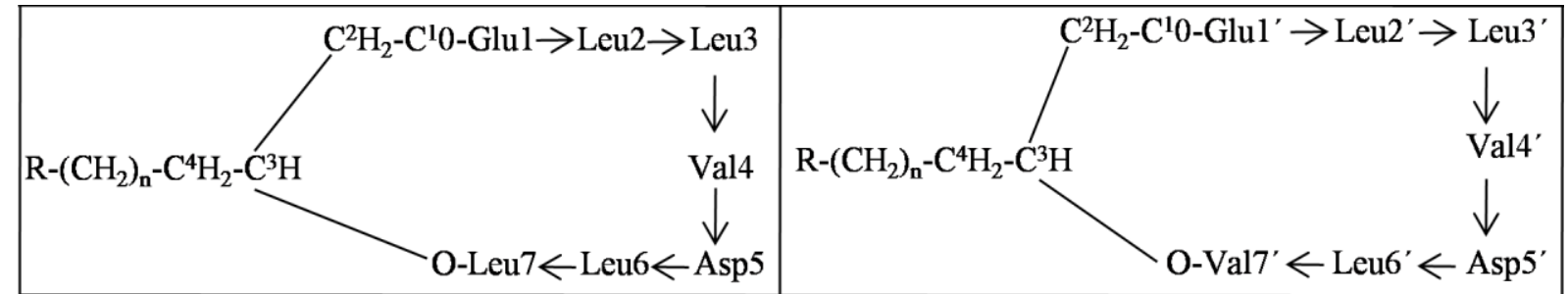

Fig. 1: Structures of Surfactin [7].

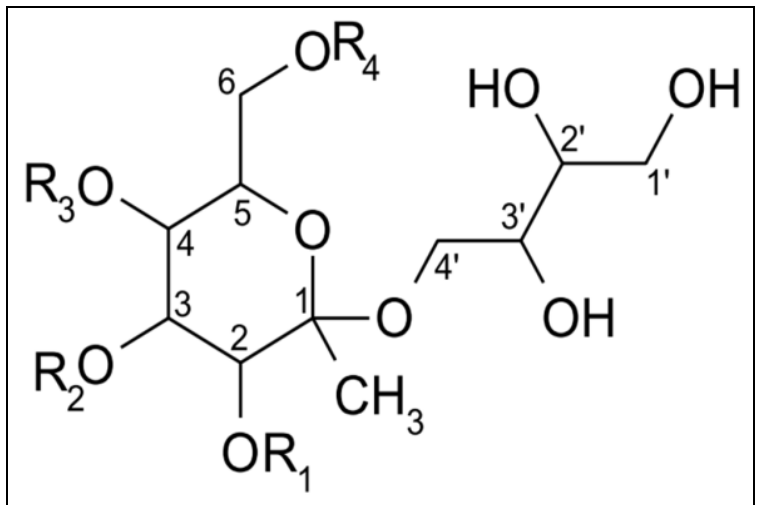

Fig. 2: Structure of MEL-B $\left(\mathrm{R}_{1}=\right.$ Acetyl Group, $\left.\mathrm{R}_{2}=\mathrm{H}\right)[6]$ 
Table 1: Central Composite Rotational Design for the Identification of Surface Activity: Surface Tension Values (ST) and Their Critical Micelle Dilutions, 10 Times (CMD-1) and 100 Times (CMD-2) Of MEL-B and Surfactin under Extreme Conditions at the Same Time

\begin{tabular}{|c|c|c|c|c|c|c|c|c|c|c|c|}
\hline \multicolumn{3}{|c|}{ Coded levels } & \multicolumn{4}{|c|}{$\begin{array}{l}\text { Experimental } \\
\text { Levels }\end{array}$} & \multicolumn{2}{|c|}{ Produced surfactin } & \multicolumn{3}{|c|}{$\begin{array}{c}\text { Produced } \\
\text { MEL-B }\end{array}$} \\
\hline 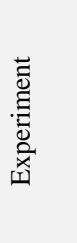 & $\bar{x}$ & $\ddot{x}$ & $\ddot{x}$ & 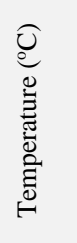 & $\frac{T}{2}$ & 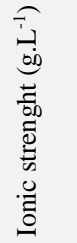 & 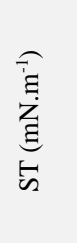 & 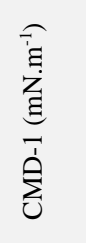 & 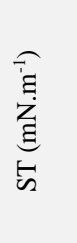 & 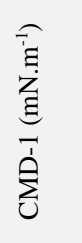 & 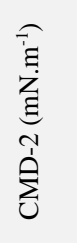 \\
\hline 1 & -1 & -1 & -1 & 87.5 & 4.02 & 6.04 & 33.38 & 48.91 & 28.25 & 29.85 & 59.90 \\
\hline 2 & +1 & -1 & -1 & 112.5 & 4.02 & 6.04 & 37.53 & 62.44 & 30.18 & 30.62 & 72.09 \\
\hline 3 & -1 & +1 & -1 & 87.5 & 9.97 & 6.04 & 37.67 & 48.29 & 27.87 & 31.32 & 57.10 \\
\hline 4 & +1 & +1 & -1 & 112.5 & 9.97 & 6.04 & 35.02 & 51.23 & 29.42 & 33.14 & 69.07 \\
\hline 5 & -1 & -1 & +1 & 87.5 & 4.02 & 16.45 & 41.27 & 72.34 & 27.50 & 34.35 & 61.28 \\
\hline 6 & +1 & -1 & +1 & 112.5 & 4.02 & 16.45 & 43.95 & 72.54 & 27.23 & 32.82 & 72.46 \\
\hline 7 & -1 & +1 & +1 & 87.5 & 9.97 & 16.45 & 45.42 & 72.54 & 27,00 & 29.24 & 50.69 \\
\hline 8 & +1 & +1 & +1 & 112.5 & 9.97 & 16.45 & 43.15 & 72.71 & 27.06 & 33.85 & 67.59 \\
\hline 10 & +1.68 & 0 & 0 & 121.0 & 7.00 & 11.25 & 46.65 & 60.95 & 27.43 & 31.25 & 70.93 \\
\hline 11 & 0 & -1.68 & 0 & 100.0 & 2.00 & 11.25 & 47.53 & 72.74 & 27.99 & 30.69 & 72.80 \\
\hline 12 & 0 & +1.68 & 0 & 100.0 & 12.00 & 11.25 & 40.94 & 63.60 & 31.63 & 44.67 & 72.31 \\
\hline 13 & 0 & 0 & -1.68 & 100.0 & 7.00 & 2.50 & 29.95 & 49.87 & 28.32 & 32.75 & 37.01 \\
\hline 14 & 0 & 0 & +1.68 & 100.0 & 7.00 & 20.00 & 42.07 & 72.21 & 26.93 & 34.58 & 47.77 \\
\hline 15 & 0 & 0 & 0 & 100.0 & 7.00 & 11.25 & 38.71 & 71.99 & 28.58 & 39.63 & 52.35 \\
\hline 16 & 0 & 0 & 0 & 100.0 & 7.00 & 11.25 & 37.36 & 70.28 & 27.72 & 34.68 & 43.83 \\
\hline 17 & 0 & 0 & 0 & 100.0 & 7.00 & 11.25 & 37.76 & 67.36 & 28.72 & 32.51 & 48.02 \\
\hline
\end{tabular}

Then based on the analysis of CCRD data, the validation experiments were carried out.

\subsection{Emulsification index}

In order to obtain the highest solubility, surfactin was solubilized in buffer $\mathrm{pH} 8.5$ at $100 \mathrm{mg} . \mathrm{L}^{-1}$ [9]. The emulsification index was measured using the method described by Cooper and Goldenberg [10], whereby $6 \mathrm{~mL}$ of each crude oil (light, medium and heavy kindly provided by CEPETRO-UNICAMP, which were collected in Brazil), benzene (Sigma-Aldrich > $99 \%$ ), toluene (SigmaAldrich $>99.3 \%$ ) and xylenes (Sigma-Aldrich $\geq 98.5 \%$ ), were added to $4 \mathrm{~mL}$ of biosurfactant solutions: surfactin standard, MEL-B standard; produced surfactin and produced MEL-B. Then, each screwcap test tube was vortexed for $2 \mathrm{~min}$. The emulsion stability was determined after $24 \mathrm{~h}\left(\mathrm{E}_{24}\right)$ and $120 \mathrm{~h}\left(\mathrm{E}_{120}\right)$ and the emulsification index was calculated by dividing the measured height of the emulsion layer by the total height of mixture and multiplying it by 100 (the height of the emulsion was measured by the software ImageJ - 1.48v - version). Each experiment was run in duplicate.

\subsection{Removal of crude oil from sand}

Artificial sand ( $3 \mathrm{~g}$ ) was vortexed with $0.3 \mathrm{~g}$ of light, medium and heavy oils, benzene, toluene and xylnenes in $20 \mathrm{~mL}$ Falcon tubes. All flasks were homogenized by shaking them at $100 \mathrm{rpm} 24 \mathrm{~h}$ at $40{ }^{\circ} \mathrm{C}$. Afterwards, $3 \mathrm{~mL}$ of biosurfactant solutions were added to each flask. The flasks were incubated at $100 \mathrm{rpm}$ and $40{ }^{\circ} \mathrm{C}$ for 24 h. Finally, the supernatants were collected and then their volumes were measured [11]. Experiment controls were performed using deionized water at the same conditions [12]. Each experiment was carried out in duplicate.

\subsection{Oil displacement test}

Deionized water $(30 \mathrm{~mL})$ was placed in $15 \mathrm{~cm}$ diameter Petri dish. Then $200 \mu \mathrm{L}$ crude oil (light, medium and heavy) was dropped onto the surface of water. Finally, $10 \mu \mathrm{L}$ of biosurfactant solutions was placed onto the surface of oil. The diameter the clear zone was measured using the software ImageJ (1.48v - version). Each experiment was run twice.

\section{Results and discussion}

\subsection{Surface activity under extreme conditions}

\subsubsection{Study of surface activity - extreme condition one at a time}

The Figs. 1, 2 and 3 show the comparative study of surface activity under extreme conditions of surfactin standard, produced surfactin, standard MEL and produced MEL solutions.

\subsubsection{Ionic strength}

It has been reported that surface activity of biosurfactants, in particular anionic, is negatively affected by electrolytes [13]. Thus, it is fundamental for the application of (bio) surfactants at industrial scale, the acquaintance of interactions between (bio)surfactant and electrolytes. In this sense, it is worth noting that electrolytes usually show negative effect on microbial growth (in situ MEOR) [14]. The ionic strength affect the surface activity of surfactin, in which the higher ionic strength, the lower was surface activity (high surface tension values of ST, CMD-1 and CMD-2) (Fig. 3).

Thimon et al. [15] evaluate the surface activity of uncomplexed surfactin solution at $\mathrm{pH} 9.5$ - tris buffer - and complexed with divalent ions $\mathrm{Ca}^{+2}$ and $\mathrm{Ba}^{+2}$ or monovalent cations $\mathrm{Li}^{+}, \mathrm{Rb}^{+}, \mathrm{Na}^{+}$, $\mathrm{K}^{+}$. Comparing with uncomplexed surfactin, the presence of all cations (complexed surfactin) resulted in lower ST values. Vass et al. [16] described the conformation change ( $\beta$ or $\gamma$-turn) of surfactin due to the presence of $\mathrm{Ca}^{2+}$ ions. The authors conclude that surfactin adopts different forms depending on $\mathrm{Ca}^{2+}$ ions. They mainly related the differences on $\mathrm{COOH}$ groups of $\mathrm{Glu}^{1}$ and $\mathrm{Asp}^{5}$, as the stabilizer-key of backbone conformation of the ring. These changes very likely affect the surface activity.

In this sense, due to the many ions that composed the synthesized brine as $\mathrm{Na}^{+}, \mathrm{Cl}^{-}, \mathrm{Ca}^{+2}, \mathrm{~K}^{+}$, etc., it is impossible to identify any synergitic or antagonistic effect on the surface tension activity. However, it is worth point out the relative low ST value even at highest ionic strength concentrations, 10 and 20 g.L. ${ }^{-1} ; 33.19$ and $40.02 \mathrm{mN} . \mathrm{m}^{-1}$, respectively (Fig. 3). These results indicate good technology prospecting on MEOR by the use of surfactin.

As expected, the surface activity of MEL was less affected by high concentrations of synthesized brine rather than surfactin (Fig. 3). These results are aligned to Kim et al. [17], in which MEL-SY16 
kept the surface tension activity up to $1000 \mathrm{mM} \mathrm{NaCl}$ and $10 \mathrm{mM}$ $\mathrm{CaCl}_{2}$.

Therefore, synthesized brine affected the surface activity of both biosurfactants. Even so, the application of surfactin and MEL-B in any system with high concentration of synthesized brine (wells) is feasible.

\subsubsection{Temperature}

Comparing with synthetic surfactants, biosurfactant showed higher stability to the extreme temperatures [7, 17]. Although, the exposure of biosurfactants at high temperatures may affect their self-aggregation forms or even lead to chemical degradation, in which both will change their surface activity.

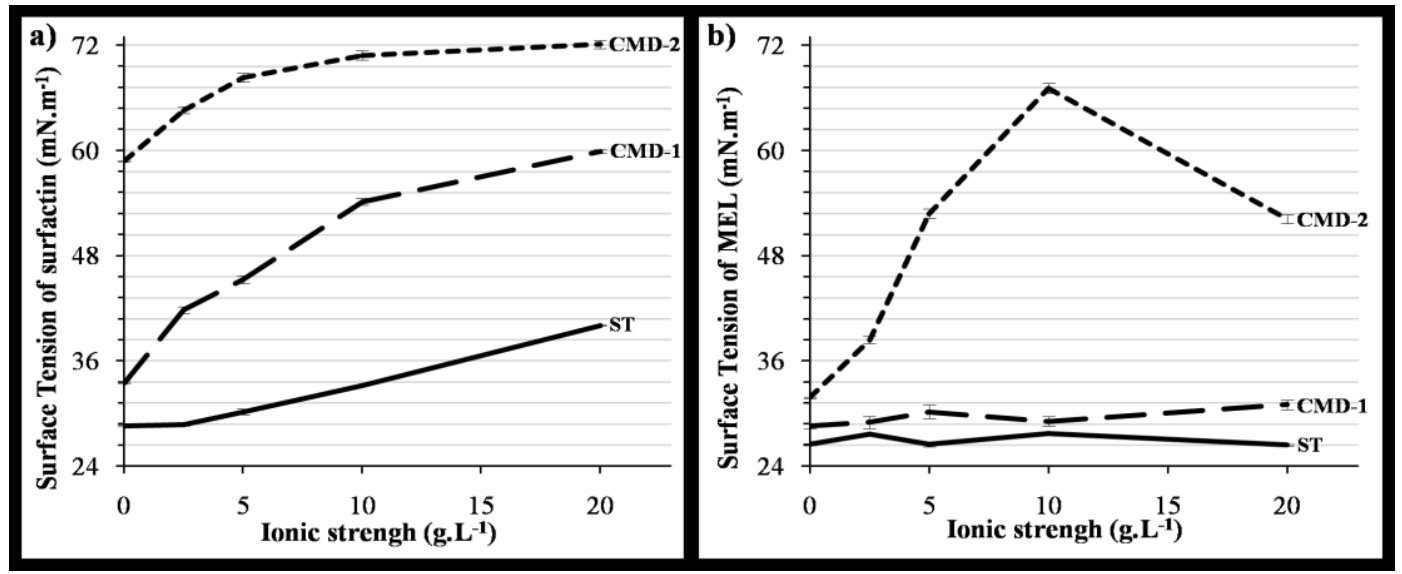

Fig. 3: Experiments of Surface Activity of Biosurfactants - Surfactin (A) and MEL (B) - at Range of Ionic Strength: Surface Tension Values (ST) and Its Critical Micelle Dilutions, 10 Times (CMD-1) and 100 Times (CDM-2) are Represented By ( $)$; ( $\mathbf{C}) ;(\boldsymbol{M})$ Curves, Respectively.
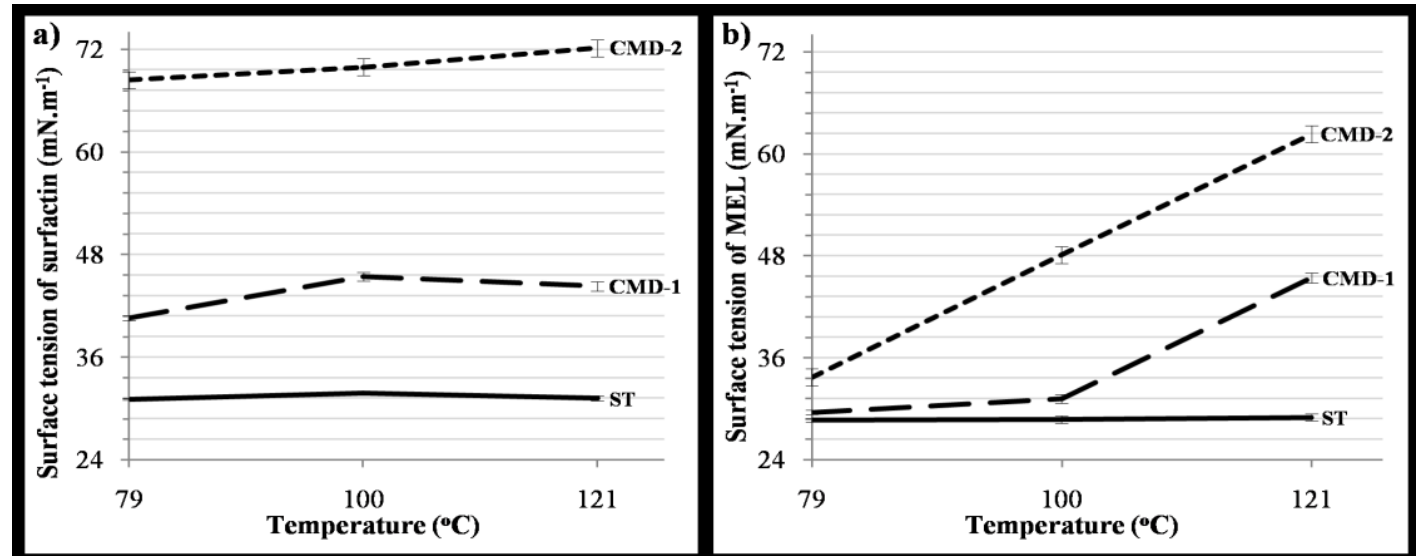

Fig. 4: Experiments of Surface Activity of Biosurfactants - Surfactin (A) and MEL (B) - after Extreme Conditions of Temperature: Surface Tension Val-

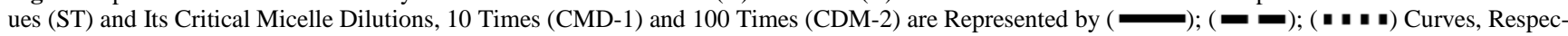
tively.

Regarding surfactin, no significant differences were observed among the ST and CMD values of thermal treatment at 79, 100 and $121^{\circ} \mathrm{C}$ (Fig. 4). Therefore, thermal treatment did not affect the surface activity of surfactin.

Kim et al. [17] reported the surface activity of MEL-SY16 after 1 $\mathrm{h}$ at $20-90{ }^{\circ} \mathrm{C}$ (thermal stability). These results are aligned to thermal treatment at $79{ }^{\circ} \mathrm{C}$ (Fig. 4), whereas the thermal treatments at 100 and $121^{\circ} \mathrm{C}$ significantly affected the surface activity of MEL.

\subsubsection{3. pH}

Ionic surfactants are very affected by $\mathrm{pH}$ changes, for instance the anionic biosurfactants surfactin precipitates at $\mathrm{pH} 2$ [2]. On the other hand non-ionic surfactants, as MEL, are more resistant to $\mathrm{pH}$ changes [18]. Thus, the surface activity of surfactin should be significant affect by $\mathrm{pH}$ changes, differently that MEL, which no or subtle changes would be observed.

It is fundamental highlighted that $\mathrm{pH}$ experiment does not evaluate the chemical stability of biosurfactants, since factors associated to decrease of solubility and changes on the self-aggregation forms are directly related to surface activity measurements. However, the hypothesis of chemical breaking of biosurfactants at extreme conditions should not disregarded.

The produced surfactin showed the highest ST and CMD values under extreme condition of $\mathrm{pH}$, that is, lowest surface activity. On one hand $\mathrm{pH} 2$ precipitates surfactin reducing the surface activity [7]. On the other hand, extreme alkaline condition may act in the surfactin micelles or breaks the surfactin structure. The intermediaries $\mathrm{pH} \approx 4$ to 8 showed the lowest $\mathrm{ST}$ and CMD values (Fig. 5). The analyses of ST and CMDs measurements of MEL (Fig. 5) indicates an abrupt increase of values from $\mathrm{pH} 10$ to 12, which could indicate the chemical breaking of MEL-B. Furthermore, a slight decreasing of CMD-1 values and a significant decreasing of CMD-2 values were observed from $\mathrm{pH} 2$ to 6 . These results followed the same trend that described by Kim et al. [17], which detailed that surface activity of MEL-SY16 was relatively stable over a $\mathrm{pH}$ range of 4 to 10 .

Therefore, both surface activities of surfactin and MEL-B were affected under extreme pHs (acid or alkaline), however, may due to different reasons. As an anionic compound, the solubility of surfactin should be significantly affected under extreme pHs, whereas the chemical structure of MEL-B may breaks under extreme $\mathrm{pHs}$.

In conclusion, the surface activity properties of both surfactin and MEL-B were affected, in different ways. The surface activity of surfactin was more affected by ionic strength and $\mathrm{pH}$, whereas surface activity of MEL-B was affected by thermal treatment (100 and $\left.121^{\circ} \mathrm{C}\right)$. 


\subsubsection{Study of surface activity - interactions}

The surface activities of surfactin and MEL under extreme condition of $\mathrm{pH}$, temperature and ionic strength were already reported [7], [17]. Although, to the best of our knowledge, this is the first study that focused on the biosurfactants surface activity under extreme conditions of $\mathrm{pH}$, temperature and ionic strength at the same time. The acquaintance of biosurfactants surface activity interactions among different conditions of temperature, $\mathrm{pH}$ and ionic strength is fundamental for MEOR. For instance, Le et al. [5] described that in the Daqing oilfield, the temperature ranged from 45 to $89^{\circ} \mathrm{C}$ and the ionic strength $\approx 15 \mathrm{~g} . \mathrm{L}^{-1}$, that is, the interactions of these parameters have to be consider. In this sense, Donaldson et al. [14] described the interface tension (oil and water) significantly decrease at $\mathrm{pKa}$ of acids in the presence of salts. Regarding CCRD of surfactin, the ANOVA of ST and CMD-1 indicates that parameters (temperature, $\mathrm{pH}$ and ionic strength) are statistically different $\left(95 \%\right.$ of confidence) $\left[\left(\mathrm{F}_{\text {calregression }} 23.02 ; \mathrm{F}_{\text {tab }}\right.\right.$

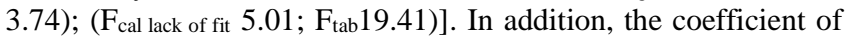
determination of CMD-1 was higher than ST ( $r^{2}$ of 0.76 ), probably due to the concentration of surfactin, which was higher or close to critical micellar concentration resulting in constant or similar values of ST. Thus, the CCRD analysis of surfactin was based only on CMD-1 rather than ST, in which was generated the following Eq:

$E q .1: Y=67.28+8.5-3.02 x^{2}$

$\mathrm{Y}$ is CMD-1 of surfactin, $\mathrm{x}$ ionic strength and $\mathrm{x}^{2}$ ionic strength squared.
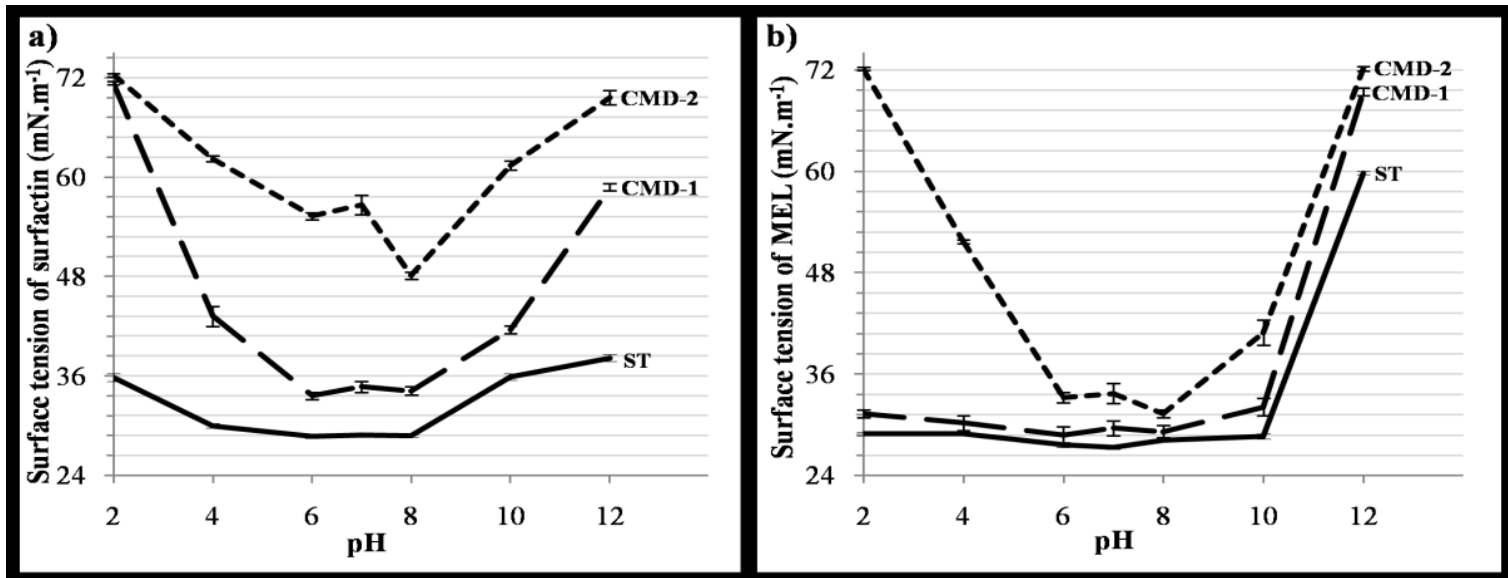

Fig. 5: Experiments of Surface Activity of Biosurfactants - Surfactin (A) and MEL (B) - at Range of Ph: Surface Tension Values (ST) and Its Critical

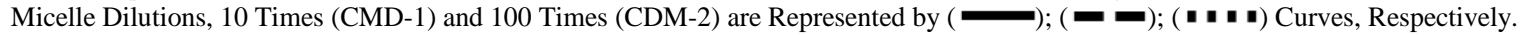
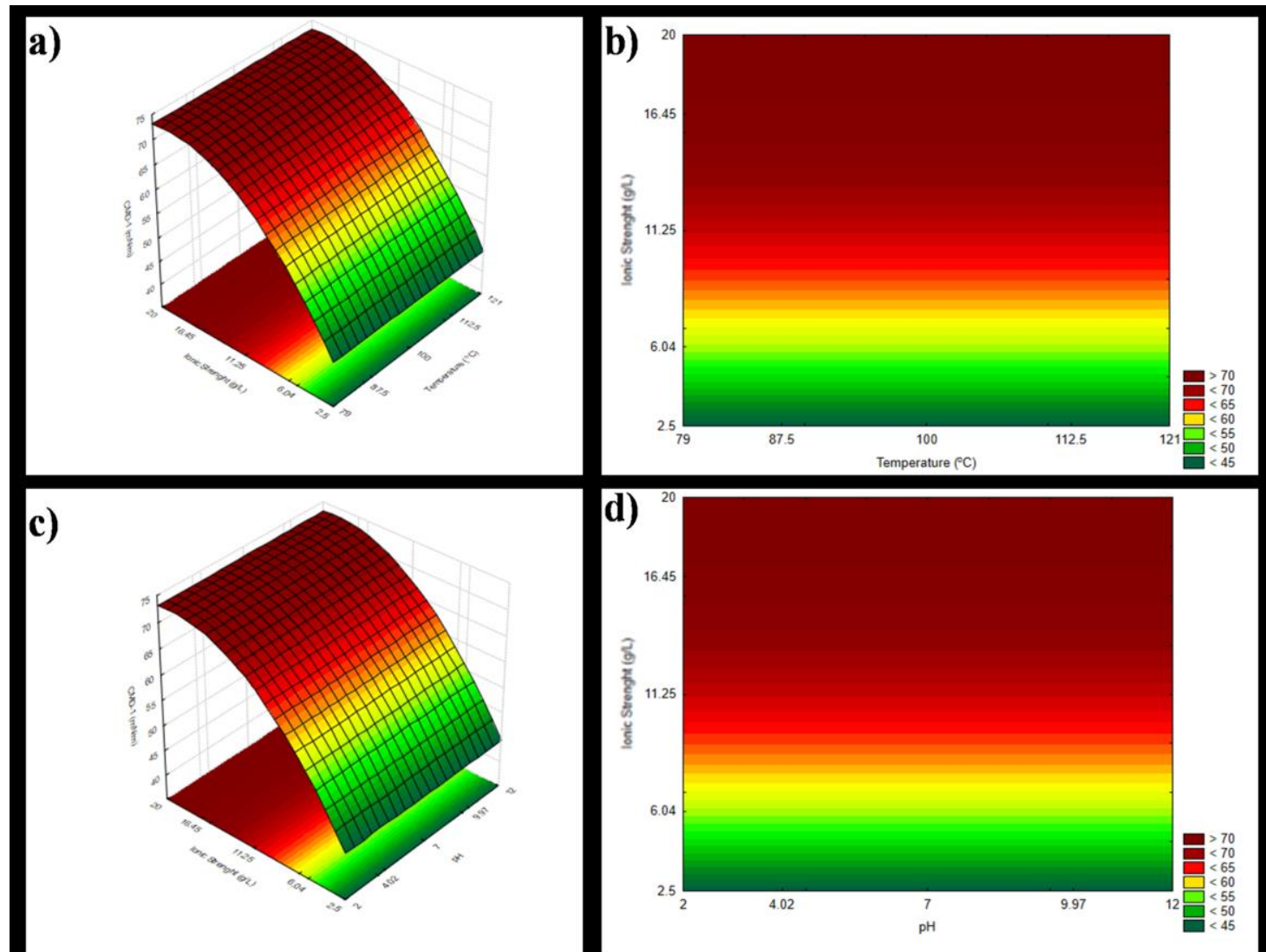

Fig. 6: Graphic of Response Surface - Critical Micelle Dilutions, 100 Times (CMD-2) of Surfactin, at Extreme Conditions pH, Ionic Strength and Temperature. 
The ionic strength is the most significant parameters on the surface activity of surfactin (Fig. 6). As shows Fig. 6, pH and thermal treatment minimally affected the surface activity of surfactin. The derivate of Eq. 1 with $\mathrm{Y}^{\prime}=0$ (maximum - red area) indicated the threshold of low surface activity was $18.58 \mathrm{~g} . \mathrm{L}^{-1}$ of brine, when associated to extreme $\mathrm{pHs}$ and thermal treatments.

Regarding CCRD of MEL-B, the ANOVA of ST, CMD-1 and CMD-2 indicated that all parameters were statistically different (95\% of confidence) $-\left[\left(\mathrm{F}_{\text {calregression }} 38.29 ; \mathrm{F}_{\text {tab }} 3.41\right)\right.$; ( $\mathrm{F}_{\text {cal lack of fit }}$ $2.17 ; \mathrm{F}_{\mathrm{tab}}$ 19.40)]. The higher coefficient of determination of CMD-2 higher than ST and CMD-1 ( $\mathrm{r}^{2}$ of 0.84$)$ occurred may due to the concentration of MEL-B, which was higher to critical micellar concentration resulting in constant or similar values for ST and CMD-1. Thus, the CCRD analysis of MEL-B was based only on CMD-2 rather than ST and CMD-1, in which was generated the following Eq:
$E q \cdot(2): Y=47.76+5 \cdot 15 x+9.16 z^{2}+5.34 w^{2}$

$\mathrm{Y}$ is CMD-2 of MEL, $\mathrm{x}$ temperature, $\mathrm{z}^{2} \mathrm{pH}$ squared and $\mathrm{w}^{2}$ ionic strength squared.

Different than surfactin, the response surface analysis of MEL-B reveled that ionic strength, $\mathrm{pH}$ and thermal treatment have significant affected the surface activity of MEL-B. Ionic strength and $\mathrm{pH}$ were squared terms, whereas, temperature linear term, that is, changes on ionic strength and $\mathrm{pH}$ are more significant parameters. The derivate of Eq. 2 with $\mathrm{Y}^{\prime}=0$ (minimum - green area) indicated that the central point was the lowest value of CMD-2. These results followed the same trend that the study of maintenance of surface activity of MEL-B - one at a time, in which $\mathrm{pH}$, thermal treatment and ionic strength affected the surface activity of MELB.

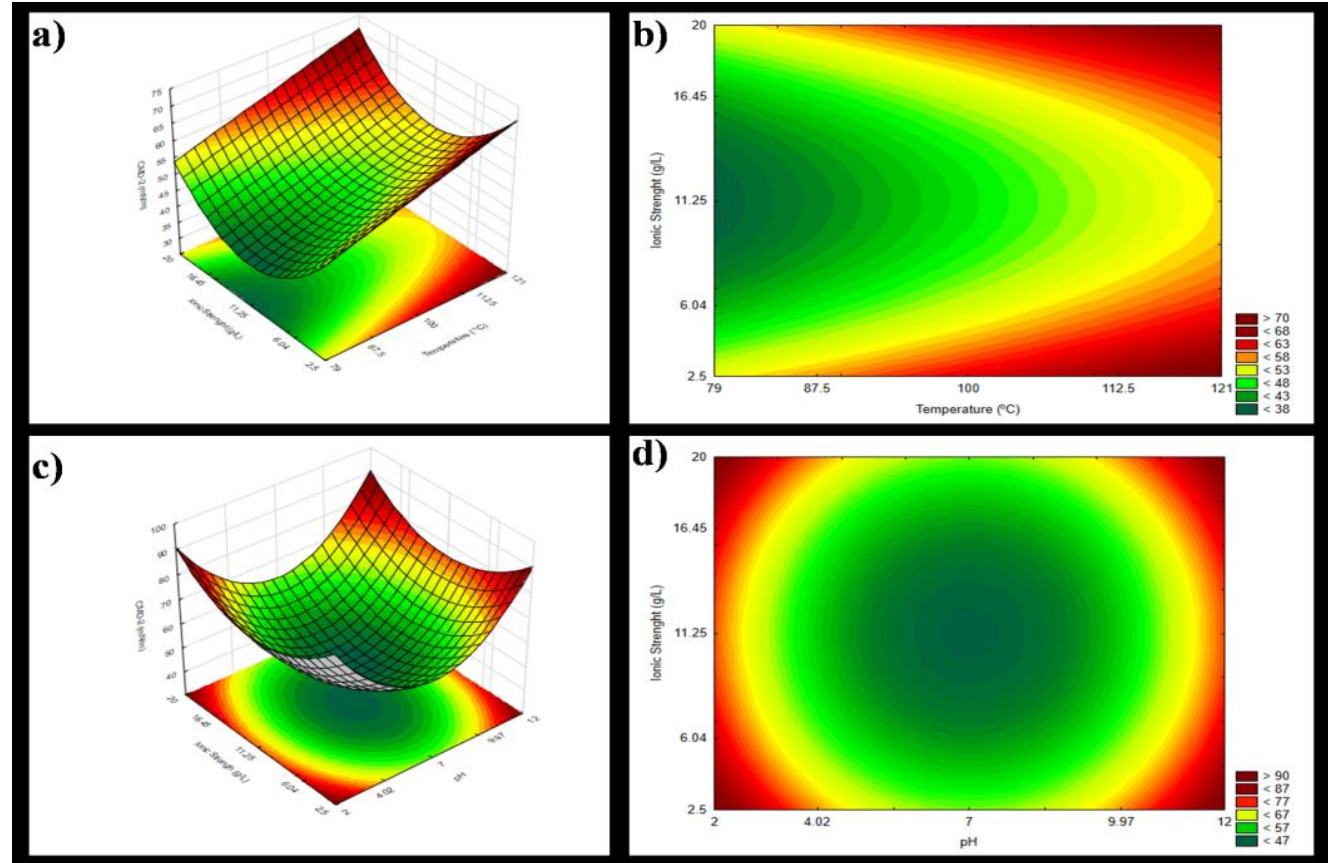

Fig. 7: Graphic of Response Surface - Critical Micelle Dilutions, 100 Times (CMD-2) of MEL-B, at Extreme Conditions pH, Ionic Strength and Temperature.

Table 2: Predicted and Experimental Data of Central Composite Design Experiments - Surfactin and MEL-B

\begin{tabular}{|c|c|c|c|c|c|c|c|c|}
\hline \multirow[b]{2}{*}{ 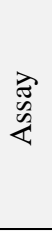 } & \multicolumn{4}{|c|}{ Surfactin } & \multicolumn{4}{|c|}{ MEL } \\
\hline & 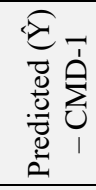 & 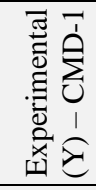 & $\begin{array}{l}-\bar{\lambda} \\
\check{Z}\end{array}$ & 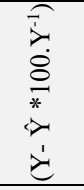 & 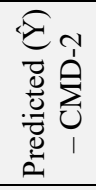 & 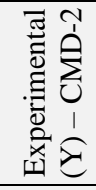 & $\begin{array}{l}-> \\
\overline{1}\end{array}$ & 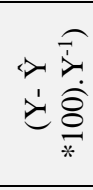 \\
\hline 1 & 55.76 & 48.91 & 6.9 & 14.01 & 57.11 & 59.90 & 2.79 & 4.66 \\
\hline 2 & 55.76 & 62.44 & 6.7 & 10.70 & 67.41 & 72.09 & 4.68 & 6.49 \\
\hline 3 & 55.76 & 48.29 & 7.5 & 15.47 & 57.11 & 57.10 & 0.01 & 0.02 \\
\hline 4 & 55.76 & 51.23 & 4.5 & 8.84 & 67.41 & 69.07 & 1.66 & 2.40 \\
\hline 5 & 72.76 & 72.34 & 0.4 & 0.58 & 57.11 & 61.28 & 4.17 & 6.80 \\
\hline 6 & 72.76 & 72.54 & 0.2 & 0.30 & 67.41 & 72.46 & 5.05 & 6.97 \\
\hline 7 & 72.76 & 72.54 & 0.2 & 0.30 & 57.11 & 50.69 & 6.42 & 12.67 \\
\hline 8 & 72.76 & 72.71 & 0.1 & 0.07 & 67.41 & 67.59 & 0.18 & 0.27 \\
\hline 9 & 67.28 & 72.50 & 5.2 & 7.20 & 39.11 & 49.44 & 10.33 & 20.90 \\
\hline 10 & 67.28 & 60.95 & 6.3 & 10.39 & 56.41 & 70.93 & 14.52 & 20.47 \\
\hline 11 & 67.28 & 72.74 & 5.5 & 7.51 & 73.61 & 72.80 & 0.81 & 1.12 \\
\hline 12 & 67.28 & 63.60 & 3.7 & 5.79 & 73.61 & 72.31 & 1.30 & 1.80 \\
\hline 13 & 44.48 & 49.87 & 5.4 & 10.82 & 62.83 & 37.01 & 25.82 & 69.77 \\
\hline 14 & 73.04 & 72.21 & 0.8 & 1.14 & 62.83 & 47.77 & 15.06 & 31.53 \\
\hline 15 & 67.28 & 71.99 & 4.7 & 6.54 & 47.76 & 52.35 & 4.59 & 8.77 \\
\hline 16 & 67.28 & 70.28 & 3.0 & 4.27 & 47.76 & 43.83 & 3.93 & 8.97 \\
\hline 17 & 67.28 & 67.36 & 0.1 & 0.12 & 47.76 & 48.02 & 0.26 & 0.54 \\
\hline
\end{tabular}


As shows in the Table 2, the predicted CMD-1 values of surfactin were very well aligned to experimental data. The difference among central points was minimal; also, the highest relative difference between predicted values and experimental values was $15.47 \%$. That proves the adjustment of model in the range studied. The most predicted CMD-2 values of MEL-B were similar to experimental.

\subsubsection{Validation of rotational central composite experi- mental design}

Regarding surfactin, the validation test was carried out with ionic strength that 1.41 coded data, that is, 18.58 g.L. $\mathrm{L}^{-1}$. Even not correlated to Eq. 1, temperature and $\mathrm{pH}$ were also included at their central points, $\mathrm{pH} 7$ and $100{ }^{\circ} \mathrm{C}$. The validation test resulted in $72.17 \mathrm{mN} . \mathrm{m}^{-1}$, which is well aligned to the predicted value is $73.26 \mathrm{mN} \cdot \mathrm{m}^{-1}$. Regarding to MEL-B, the validation was carried out using the central point, that is, 11.25 g. $\mathrm{L}^{-1}, \mathrm{pH} 7$ and $100{ }^{\circ} \mathrm{C}$. The validation (MEL-B) resulted in $48.52 \mathrm{mN} . \mathrm{m}^{-1}$, which is similar to predicted value $47.76 \mathrm{mN} . \mathrm{m}^{-1}$.

Therefore, the validation data confirmed the relation between surface activities (surfactin and MEL-B) and extreme conditions ( $\mathrm{pH}$, ionic strength and temperature).

\subsection{Oil displacement test}

It was already reported that the clear zone of oil displacement is directly proportional to the concentration of biosurfactants - from 50 to $2000 \mathrm{mg} . \mathrm{L}^{-1}$ - with crude oil and surfactin, $\mathrm{r}^{2}$ of 0.997 [1921]. Morikawa et al. [20] reported a $72 \mathrm{~cm}^{2}$ clear zone using crude oil and surfactin solution at $1036.3 \mathrm{mg} . \mathrm{L}^{-1}$. They also evaluated the effect of $\mathrm{pH}$ on oil displacement and concluded that the highest areas were obtained using alkaline pHs. Bharali et al. [19] described that areas obtained from oils displacement test between $0.308-0.375 \mathrm{~cm}^{2}$ using a $10 \mu \mathrm{L}$ biosurfactant solution at 20.000 mg. $L^{-1}$.

Regarding this study, the produced biosurfactants showed the same trend that biosurfactant standards, that is, MEL-B obtained higher clear zone and was more suitable for heavy oil rather than medium and light oils (Table 3, Fig. 8). However, it worth noting that the produced biosurfactants were at different concentrations: produced MEL-B was at $\approx 870 \mathrm{mg} . \mathrm{L}^{-1}$ and produced surfactin at $73.74 \mathrm{mg} \cdot \mathrm{L}^{-1}$.

Table 3: Clear Zone $\left(\mathrm{Cm}^{2}\right)$ of Surfactin and MEL (Standard and Produced) on Light, Medium and Heavy Oils

\begin{tabular}{lcccc}
\hline & Standard surfactin & Standard MEL-B & Produced surfactin & Produced MEL-B \\
\hline Light oil & 1.27 & 2.87 & 1.98 & 6.32 \\
Medium oil & 3.77 & 5.91 & 1.46 & 11.80 \\
Heavy oil & 4.49 & 6.78 & 3.97 & 15.78 \\
\hline
\end{tabular}

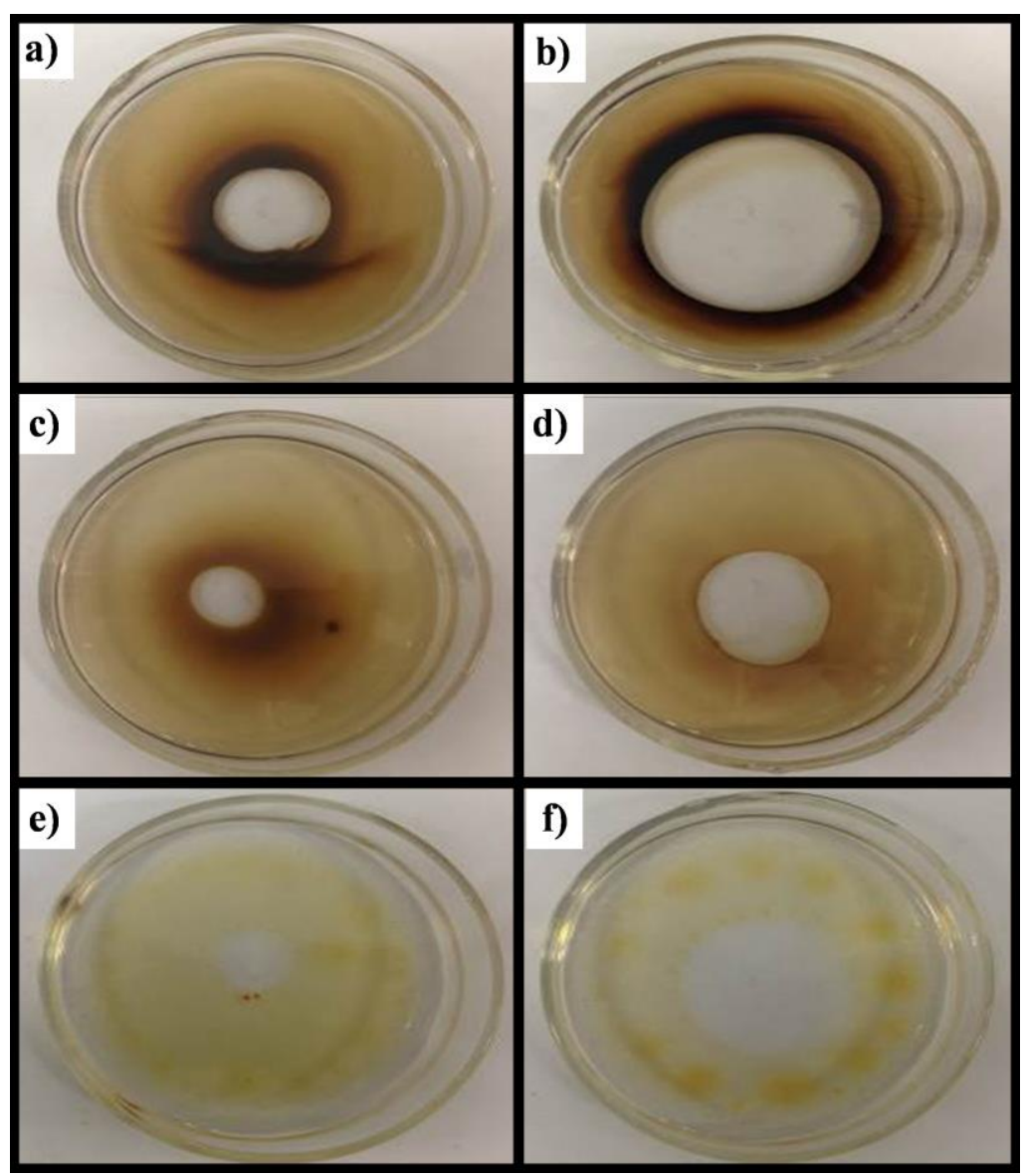

Fig. 8: Oil Displacement Test: A) Produced Surfactin - Heavy Oil; B) Produced MEL -Heavy Oil; C) Produced Surfactin - Medium Oil; D) Produced MEL - Medium Oil; E) Produced Surfactin - Light Oil; F) Produced MEL - Light Oil.

Both biosurfactant (standard) showed the highest clear zones with heavy oil at $100 \mathrm{mg} . \mathrm{L}^{-1}$ (heavy oil > medium oil > light oil). In addition, MEL-B showed higher area than surfactin, when at the same concentration 100 mg.L $\mathrm{L}^{-1}$ (Table 3, Fig. 8).

\subsection{Application of biosurfactants in removal of crude oil from sand}

The main toxic compounds of crude oil are benzene, ethyl benzene, toluene, xylenes [22]. The differences between MEL-B and 
surfactin standards on the removal of light and medium oils, benzene, toluene and xylenes from sand were minimal (Table 4). Although, compared with surfactin, MEL-B showed higher volume of heavy oil that was recovered. These results followed the same trend that the oil displacement test. In addition, the similar results with benzene, toluene and xylenes indicated that both biosurfactants have a good prospecting on the bioremediation (crude oilcontaminated soil). Deionized water did recovery oil (similarly to secundary recovery processes), however the results with deionized water were subtle lower than all biosurfactants and higher concen-

tration of both biosurfactants solution, probably would improve the yields of oil recovery.

Therefore, it could be assumed that both biosurfactants enhanced the removal of crude oil from sand, in particular for heavy oil.

\subsection{Emulsification index}

Table 4: Removal of Crude Oil from Sand

\begin{tabular}{lccccc}
\hline & Deionized water & Standard surfactin & Produced surfactin & Standard MEL-B & Produced MEL-B \\
\hline Light oil & 0.71 & 0.75 & 0.80 & 0.80 & 0.83 \\
Medium oil & 0.79 & 0.82 & 0.81 & 0.80 & 0.79 \\
Heavy oil & 0.79 & 0.78 & 0.71 & 0.75 & 0.87 \\
Benzene & 0.74 & 0.68 & 0.80 & 0.77 & 0.71 \\
Toluene & 0.70 & 0.77 & 0.80 & 0.78 & 0.73 \\
Xylenes & 0.77 & 0.78 & & \\
\hline
\end{tabular}

*Recovered volume/Initial volume.
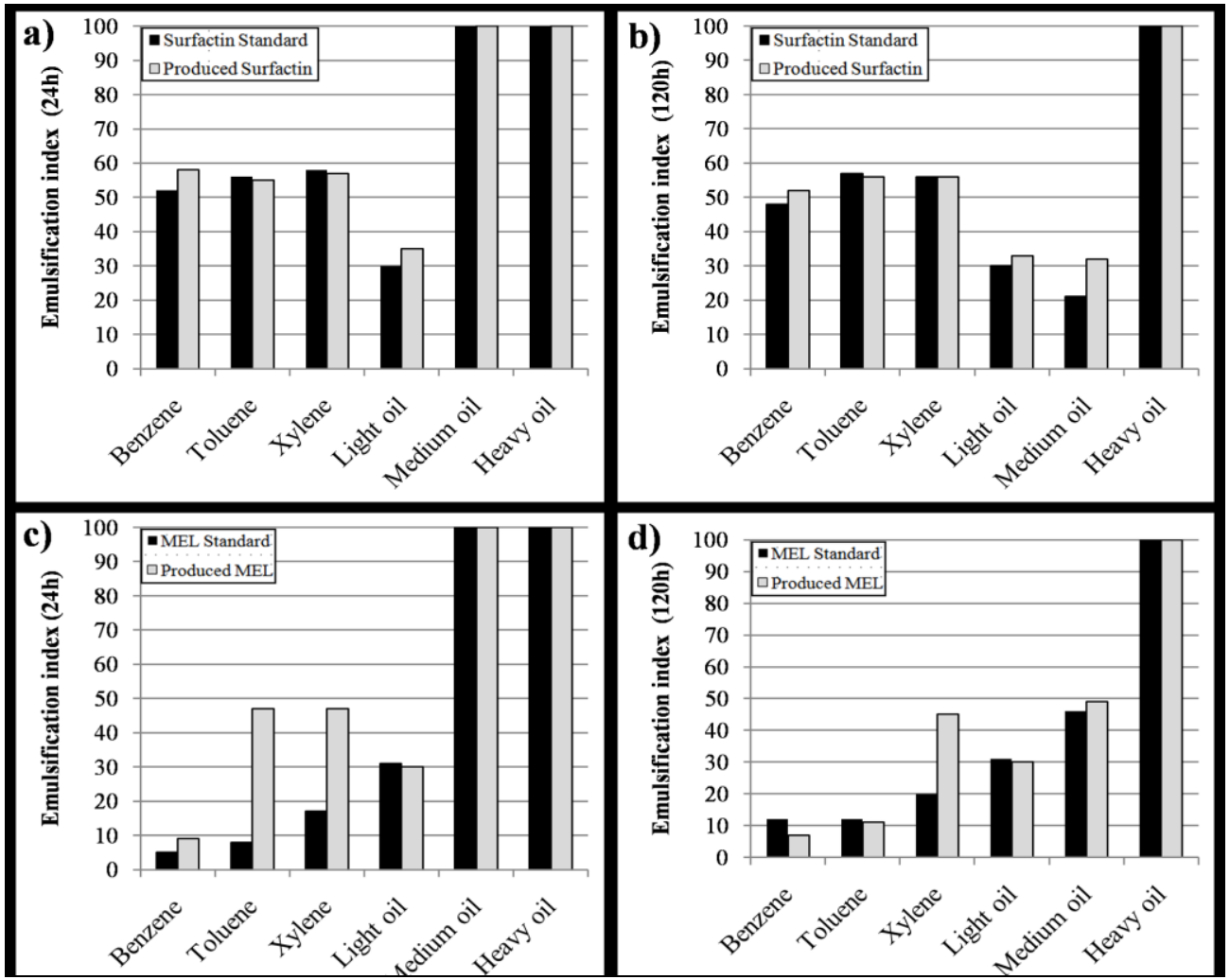

Fig. 9: Emulsification Index (\%) of Produced MEL-B and Surfactin in Crude Oils and Toxic Compounds of Oils.

In general, all toxic compounds (benzene, toluene and xylenes) presented stable emulsion up to $120 \mathrm{~h}$ (Fig. 9). In this sense, surfactin (standard and produced) showed higher emulsification indexes than MEL-B (standard and produced).

The light oil showed the lowest emulsification indexes. However, they resulted in stable emulsions up to $120 \mathrm{~h}$. The medium oil presented emulsification indexes of $100 \%$ for surfactin and MEL$\mathrm{B}$, but they were unstable at $120 \mathrm{~h}$. On the other hand, heavy oil showed the highest emulsification indexes, which were stable up to $120 \mathrm{~h}$. Thus, surfactin and MEL are more feasible for emulsion with heavy oil rather than light and medium oils.

Therefore, surfactin and MEL-B are indicated as emulsifiers for crude oils, in particular heavy oils. These results are aligned to oil displacement test and removal of crude oil from sand data.

In conclusion, all three experiments (i) the oil displacement, (ii) removal of crude oil from sand and (iii) emulsification index indicated a better prospecting of MEOR with heavy oil.

Very likely MEOR will be consolidated technique that applies (directly or indirectly) biosurfactant and other biocompounds to- gether. A well-known example of those metabolic product mixtures is named PIMP (obtained by Pseudomonas aeruginosa) [4].

\section{Conclusion}

Probably, MEOR will be an effective methodology in the late period of oilfield exploration. Regarding the data from the experiments one a time ( $\mathrm{pH}$, temperature and ionic strength), the surface activity of surfactin was more affected by ionic strength and $\mathrm{pH}$, whereas the surface activity of MEL-B by thermal treatment. The CCRD indicated that the ionic strength was the most significant parameter on the surface activity of surfactin, whereas $\mathrm{pH}$, thermal treatment and ionic strength significantly affected the surface activity of MEL-B. The oil displacement, removal of crude oil from sand and emulsification index tests indicated a better prospecting of MEOR with heavy oil rather than medium and light oils. 


\section{References}

[1] Zou C, Wang M, Xing Y, Lan G, Ge T, Yan X, Gu T, Characterization and optimization of biosurfactants produced by Acinetobacter baylyi ZJ2 isolated from crude oil-contaminated soil sample toward microbial enhanced oil recovery applications. Biochemical Engineering Journal, 2014, 90: 49-58. https://doi.org/10.1016/j.bej.2014.05.007.

[2] Shibulal B, Al-Bahry S. N, Al-Wahaibi Y. M, Elshafie A. E, AlBemani A. S, Joshi S. J, Microbial enhanced heavy oil recovery by the aid of inhabitant spore-forming bacteria: An insight review. The Scientific World Journal, 2014, 2014: 1-12. https://doi.org/10.1155/2014/309159.

[3] EPA - U.S. Environmental Protection Agency. Screening-level haz ard characterization. Petroleum Coke Category sponsored chemicals Petroleum coke. Green CASRN 64741-79-3 Petroleum coke. Calcined CASRN 64743-05-1. Hazard Characterization Document http://www.epa.gov/chemrtk/hpvis/hazchar/Category_Petroleum\%2 0Coke_June_2011.pdf. Accessed September 10, 2015.

[4] Patel J, Borgohain S, Kumar M, Rangarajan V, Somasundaran P, Sen R, Recent developments in microbial enhanced oil recovery, Renewable and Sustainable Energy Reviews, 2015, 52: 1539-1558. https://doi.org/10.1016/j.rser.2015.07.135.

[5] Le J. J, Wu X. L, Wang R, Zhang J. Y, Bai L. L, Hou Z. W, Progress in pilot testing of microbial-enhanced oil recovery in the Daqing oilfield of north China. International Biodeterioration \& Biodegradation, 2015, 97: 188-194 https://doi.org/10.1016/j.ibiod.2014.10.014

[6] Andrade CJ, Barros FFC, Pastore GM. Processo de obtenção de manosileritritol lipídios (MEL), composições e usos das mesmas BR 10.2015.019108.1 (Patent). August 10, 2015.

[7] Andrade C. J, Barros F. F. C, Andrade L. M, Rocco S. A, Sforça M. L, Pastore G. M, Jauregi P, Ultrafiltration based purification strategies for surfactin produced by Bacillus subtilis LB5A using cassava wastewater as substrate. Journal of Chemical Technology and Biotechnology, 2016, https://doi.org/10.1002/jctb.4928.

[8] Khajepour H, Mahmoodi M, Biria D, Ayatollah S, Investigation of wettability alteration through relative permeability measurement during MEOR process: A micromodel study. Journal of Petroleum Science and Engineering, 2014, 120: 10-17. https://doi.org/10.1016/j.petrol.2014.05.022.

[9] Jauregi P, Coutte F, Catiau L, Lecouturier D, Jacques P, Micelle size characterization of lipopeptides produced by $B$. subtilis and their recovery by the two-step ultrafiltration process, Separation and Purification Technology, 2013, 104: 175-182. https://doi.org/10.1016/j.seppur.2012.11.017.

[10] Cooper D. G, Goldenberg B. G, Surface-active agents from two Bacillus species. Applied and Environmental Microbiology, 1987, 53: 224-229.

[11] Liu Q, Lin J, Wang W, Huang H, Li S, Production of surfactin isoforms by Bacillus subtilis BS-37 and its applicability to enhanced oil recovery under laboratory conditions. Biochemical Engineering Journal, 2015, 93: 31-37. https://doi.org/10.1016/j.bej.2014.08.023.

[12] Pereira J. F. B, Gudiña E. J, Costa R, Vitorino R, Teixeira J. A, Coutinho J. A. P, Rodrigues L. R, Optimization and characterization of biosurfactant production by Bacillus subtilis isolates towards microbial enhanced oil recovery applications. Fuel, 2013, 111: 259 268. https://doi.org/10.1016/j.fuel.2013.04.040.

[13] Bai G, Brusseau M. L, Miller R. M, Influence of cation type, ionic strength, and $\mathrm{pH}$ on solubilization and mobilization of residual hydrocarbon by a biosurfactants, Journal of Contaminant Hydrology, 1998, 30: 265-279. https://doi.org/10.1016/S0169-7722(97)00043-0.

[14] Donaldson E. C, Chilingarian G. V, Yen T. F, Microbial Enhanced Oil Recovery. Elsevier Science, London, 1989.

[15] Thimon L, Peypoux F, Michel G, Interactions of surfactin, a biosurfactants from Bacillus subtilis, with inorganic cations, Biotechnology Letters, 1992, 14: 713-718. https://doi.org/10.1007/BF01021648.

[16] Vass E, Besson F, Majer Z, Volpon L, Hollósi M, $\mathrm{Ca}^{2+}$-Induced changes of surfactin conformation: A FTIR and circular dichroism study, Biochemical and Biophysical Research Communications, 2001, 282: 361-367. https://doi.org/10.1006/bbrc.2001.4469.

[17] Kim H. S, Jeon J. W, Kim S. B, Oh H. M, Kwon T. J, Yoon B. D, Surface and physico-chemical properties of a glycolipid biosurfactant mannosylerythritol lipid, from Candida antarctica, Biotechnology Letters, 2002, 24: 1637-1641. https://doi.org/10.1023/A:1020309816545.

[18] Sineriz F, Hommel R. K, Kleber H. P, Production of biosurfactants, Unesco-Eolls Publishers Oxford, 2001.
[19] Bharali P, Das S, Konwar B. K, Thakur A. J, Crude biosurfactant from thermophilic Alcaligenesfaecalis: Feasibility in petro-spill bioremediation, International Biodeterioration \& Biodegradation, 2001, 65: 68-690. https://doi.org/10.1016/j.ibiod.2011.04.001.

[20] Morikawa M, Hirata Y, Imanaka T, A study on the structure function relationship of lipopeptide biosurfactants, Biochimica et Biophysica Acta (BBA) - Molecular and Cell Biology of Lipids, 2000, 1488: 211-218. https://doi.org/10.1016/S1388-1981(00)00124-4.

[21] Youssef N. H, Duncan K. E, Nagle D. P, Savage K. N, Knapp R. M McInerney M. J, Comparison of methods to detect biosurfactant production by diverse microorganisms, Journal of Microbiological Methods, 2004, 56: 339-347. https://doi.org/10.1016/j.mimet.2003.11.001.

[22] Andrade J. A, Augusto F, Sales I. C, Jardim F, Biorremediação de solos contaminados petróleo e seus derivados, Eclética Química, 2010, 35: 17-43. 